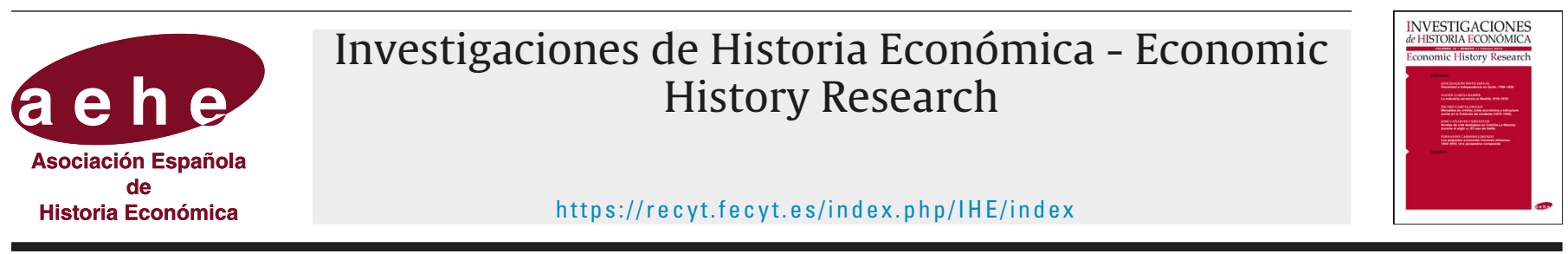

Artículo

\title{
Rotación e irregularidad del trabajo en un distrito industrial exportador. La industria corchotaponera (1891-1910)
}

\author{
Rosa Ros Massana* \\ Universitat de Girona. Centre de Recerca d'Història Rural i Departament d'Economia
}

INFORMACIÓN DEL ARTÍCULO

Historia del artículo:

Recibido el 1 de junio de 2018

Aceptado el 8 de octubre de 2018

On-line el 4 de febrero de 2020

\section{Códigos JEL:}

$\mathrm{J} 63$

R23

N33

Palabras clave:

Rotación del trabajo

Irregularidad del trabajo

Manufactura corchera

Distritos industriales

\section{R E S U M E N}

Este artículo analiza, a partir de las nóminas de dos empresas, las pautas laborales sumamente irregulares en la industria corchotaponera catalana, resultado de una gestión flexible del trabajo por parte de unas empresas muy expuestas a la competencia internacional, pero también de la pervivencia de formas tradicionales de ocio en un sector caracterizado por una fuerte cultura de oficio. La organización del sector en forma de distrito industrial, que facilitaba la circulación de trabajadores cualificados y que permitía la producción a domicilio, tuvo un papel crucial en la configuración de estas pautas laborales.

(C) 2018 Asociación Española de Historia Económica.

\section{Worker turnover and irregular labour patterns in an exporting industrial district. The cork stopper industry (1891-1910)}

A B S T R A C T

This article draws on the payroll books of two companies to analyse the highly irregular work patterns in the Catalan cork industry, which were the result of flexible labour management by companies that were very much exposed to international competition, but also of the survival of traditional forms of leisure in a sector characterized by a strong craft culture. The fact that the sector was organized as an industrial district, which facilitated the turnover of skilled workers and allowed household production, played a crucial role in shaping these labour patterns.

\section{JEL classification:}

J63

Keywords:

Worker turnover

Irregular labour patterns

Cork manufacture

Industrial districts
C 2018 Asociación Española de Historia Económica.

\footnotetext{
* Autor para correspondencia.

Correo electrónico: rosa.ros@udg.edu (Rosa Ros Massana)
} 


\section{Introducción}

Uno de los temas clásicos de la historia del trabajo es el que ha analizado la transición desde las pautas laborales sumamente irregulares propias de las manufacturas prefabriles hacia la regularización (e intensificación) de los tiempos de trabajo que comportó la fábrica moderna ${ }^{1}$. No obstante, sobre todo desde los años ochenta, esta interpretación ha sido objeto de numerosos matices que han atenuado el estrecho vínculo que los primeros estudios establecían entre estos fenómenos y la mecanización fabril. Por una parte, se ha sugerido que la intensificación y el mayor control empresarial del trabajo también se produjeron en sectores y empresas no mecanizadas antes y durante la revolución industrial ${ }^{2}$. Por la otra, se ha señalado que incluso en aquellos sectores donde dominaba la fábrica existieron formas organizativas, como la subcontratación interna, que implicaban un protagonismo y un importante grado de autonomía de los trabajadores cualificados en el control de los tiempos y la intensidad del trabajo. El hecho de que la industrialización tuviera lugar partiendo de distintas realidades previas y con distintas (y cambiantes) correlaciones de fuerzas, conllevó el desarrollo de formas de organización del trabajo de características muy variadas, con diferentes implicaciones por lo que respecta al control y los tiempos de trabajo, incluso cuando los condicionantes técnicos eran similares ${ }^{4}$.

Otras investigaciones han abordado el tema de los cambios en la rotación de trabajadores entre distintas empresas durante la industrialización ${ }^{5}$. Aunque es evidente que existen conexiones entre ambos fenómenos, estas dos líneas de investigación se han desarrollado de forma bastante independiente porque las transformaciones principales en uno y otro aspecto se han situado en distintos periodos y ámbitos geográficos. Así, mientras que la regularización de los tiempos de trabajo ha sido considerada un cambio ligado a los inicios del sistema de fábrica, la reducción sustancial de los niveles de rotación laboral no habría tenido lugar hasta el desarrollo de los mercados internos de trabajo, que los autores que introdujeron esta noción situaban en los Estados Unidos del primer tercio del siglo $\mathrm{xx}^{6}$.

La mayoría de estudios señalan que en las manufacturas prefabriles imperaba una elevada rotación de trabajadores debido tanto a factores de demanda (fluctuaciones en las ventas, estacionalidad de muchas actividades) como a factores de oferta, especialmente los relacionados con la pluriactividad. Incluso en los talleres urbanos agremiados, que se han asociado a una imagen de estabilidad y continuidad, una minoría de trabajadores estables coexistía con gran número de eventuales con elevadas tasas de rotación ${ }^{7}$. Esta marcada inestabilidad persistió en muchas industrias durante las primeras fases de

\footnotetext{
${ }^{1}$ Thompson (1979); Rule (1981); Reid (1976).

${ }^{2}$ El argumento sobre la intensificación del trabajo se ha esgrimido en la literatura sobre la "revolución industriosa" (De Vries, 2009). Sobre la evolución del tiempo de trabajo, Voth (2000).

3 Lazonick (1979); Gordon et al.(1986, pp. 29-31 y 71-127).

${ }^{4}$ Ver las reflexiones de Garcia Balañà (2004).

${ }^{5}$ Jacoby (1988); Jacoby y Sharma (1992); Carter y Savoca (1990); Owen (1995); Brown y Neumeier (2001).

${ }^{6}$ Doeringer y Piore (1985); Jacoby (1988).

7 Sonenscher (1989:158-165); Stephenson (2018).
}

la industrialización ${ }^{8}$, especialmente en algunos segmentos de la fuerza de trabajo, frecuentemente el femenino e infantil. Factores de oferta, especialmente el interés de los trabajadores en compatibilizar el trabajo industrial con otras actividades productivas o reproductivas básicas para su economía familiar, se combinaban con el interés empresarial de mantener la flexibilidad de los costes laborales ${ }^{9}$. No obstante, estos mercados de trabajo extremadamente flexibles coexistieron con el desarrollo -en algunas empresas, sectores o segmentos de la fuerza de trabajo- de mercados internos informales, a veces basados en la capacidad de los trabajadores de imponer determinadas condiciones, a veces relacionados con prácticas clientelares de los fabricantes, que tendieron a estabilizar las plantillas ${ }^{10}$.

Así pues, los niveles de irregularidad del trabajo fueron muy diversos en la primera etapa de la industrialización y dependieron de numerosos factores, entre los que la tecnología, la escasez relativa de fuerza de trabajo, su composición según género o edad, o la fuerza de las tradiciones de oficio y de las organizaciones obreras, han sido algunos de los más destacados. Este trabajo, cuyo primer objetivo es cuantificar, para el caso de la industria corchotaponera de fines del siglo xix e inicios del xx, la rotación de los trabajadores entre distintas empresas y la irregularidad de las jornadas trabajadas en una misma empresa, tratará también de ahondar en los factores que incidían en estas variables. Se sostendrá la idea de que las características de la tecnología y de los mercados, las tradiciones artesanas y la organización de esta manufactura en forma de distrito industrial, conformaron un sistema tecno-laboral (incorporando a este concepto el papel de los mercados y de la aglomeración territorial ${ }^{11}$ ) caracterizado por una fuerte irregularidad del trabajo.

\section{La manufactura corchera (c. 1850-1914)}

La manufactura corchera presentaba en la España de la segunda mitad del siglo xix e inicios del xx diversas características que la diferenciaban de otros sectores industriales. La primera era su carácter exportador (durante todo el período aquí considerado apenas dirigía al mercado español el $1 \%$ de su producción ${ }^{12}$ ), que la exponía más a la competencia en comparación con otras industrias españolas, especialmente en un período, el de fines del siglo xix e inicios del xx, en que la transformación del corcho había experimentado un desarrollo notable en otros países, sobre todo Alemania y Estados Unidos ${ }^{13}$.

\footnotetext{
${ }^{8}$ La brevedad de los períodos de permanencia en el puesto de trabajo en los Estados Unidos antes de 1914 es destacada por Owen, 1995 o Jacoby y Sharma, 1992, pero discutida por Carter y Savoca (1990). Sobre la Alemania anterior a 1914, Brown y Neumeier (2001).

${ }^{9}$ Haciendo solo referencia al caso español, Muñoz Abeledo (2010), Gálvez (2000), Sancho (2004), Vicente (2000), Ferrer Alòs (1994).

${ }^{10}$ Sobre el desarrollo de mercados internos de trabajo informales en el algodón británico, Huberman (1996); para el textil catalán, Camps (1995:181-215) y Enrech (2005:101-110).

${ }^{11}$ El concepto de sistema tecno-laboral fue acuñado hace años por Lipartito (1994) para referirse a las interrelaciones estables entre tecnología, organización del trabajo y cultura obrera que condicionaban la trayectoria del cambio tecnológico.

${ }_{12} \operatorname{Medir}(1953$, p. 283); Parejo (2010, p. 12). Sobre las redes de exportación de tapones, Ros y Sala (2014).

${ }_{13}$ Medir (1953, pp. 111-219); Zapata (2002); Parejo (2010, pp. 40-42).
} 
En segundo lugar, se trataba de una industria que se mecanizó muy tardíamente. Todavía en vísperas de la Gran Guerra las máquinas de hacer tapones se utilizaban principalmente para la elaboración de calidades inferiores, mientras que los tapones de mayor valor se seguían fabricando a mano ${ }^{14}$. Esta mecanización limitada respondía en parte a razones técnicas porque, aplicada a una materia prima físicamente heterogénea, la máquina desperdiciaba gran cantidad de corcho, lo que la hacía poco competitiva, especialmente en el segmento de mayor calidad. También porque mientras no se mecanizó la producción de botellas de vidrio la mayor heterogeneidad de formas y dimensiones que producía la manufactura taponera tradicional se adaptaba mejor a la escasa estandarización de los recipientes ${ }^{15}$. Ello implicaba que, aunque existía trabajo femenino y de otros colectivos de bajos salarios, el proceso productivo dependía crucialmente de los trabajadores de oficio, que desde los orígenes de esta manufactura en el siglo xvIII habían conseguido mantener su carácter cualificado. Los taponeros eran descritos como trabajadores orgullosos de su oficio, bien pagados, indisciplinados y con capacidad de marcar sus propios ritmos de trabajo, que eran considerablemente irregulares ${ }^{16}$.

En tercer lugar, se trataba de un sector muy concentrado territorialmente. Pese al desarrollo de actividades de transformación del corcho en el suroeste peninsular, la provincia de Girona, lugar de origen de esta manufactura en el setecientos, siguió reteniendo gran parte del negocio industrial en la segunda mitad del siglo xix ${ }^{17}$, cuando esta actividad, en fuerte expansión, pasó de ocupar a 7769 trabajadores en 1865 a más de 10000 en la década de 1890 y a unos 18000 en $1914^{18}$. Además, en dicha provincia, la manufactura corchera se concentraba en dos áreas fuertemente interconectadas: la primera en la costa del Ampurdán y la Selva (Palafrugell, Sant Feliu de Guíxols, Calonge, Palamós, Tossa, Lloret), incluyendo algunas localidades interiores al pie del macizo de las Gavarres (Cassà de la Selva, Llagostera); la segunda, de menor importancia, en la frontera con Francia, donde destacaban los pueblos de Agullana y Darnius.

Esta industria fuertemente concentrada geográficamente se configuró como un distrito industrial ${ }^{19}$. Destacaremos dos de los rasgos de estas aglomeraciones manufactureras que incidieron especialmente en el funcionamiento del mercado laboral. En primer lugar, la existencia de una amplia oferta de trabajo con las cualificaciones específicas del sector, que derivaba de la marcada especialización de las localidades corcheras. Los distintos censos de población de inicios del siglo xx indican que los hombres ocupados en el corcho eran entre el $30 \%$ y el $45 \%$ de los mayores de 15 años, existiendo además un número difícil de determinar de mujeres trabajando en el sector. En segundo lugar, la fuerte interconexión entre empresas, mayoritariamente de tamaño pequeño y mediano. Según Giménez Guited, en 1862 existían 152 empresas, con una media de

\footnotetext{
14 Espadalé (2002).

15 Sala (1998).

${ }^{16}$ Roger (1911, pp. 35-37).

17 Zapata (1996, pp. 38-44).

${ }^{18}$ Martínez Quintanilla (1865, pp. 317); Vila Saglietti (1892, pp. 68-69); Serrat Banquells (1897, p. 72); Pelegrí (1919, p. 13).

${ }^{19}$ Becattini (1987). Una síntesis interpretativa en Catalan et al. (2011, pp. 10-34); sobre este concepto en la manufactura corchera, Sala (1998).
}

30 trabajadores y un máximo de 60 , pero esta fuente infravalora notablemente las pequeñas unidades productivas, ya que no incluye las de menos de 14 obreros $^{20}$. Da medida de esta infravaloración el hecho de que en las mismas fechas el 43,5\% de las empresas de Palafrugell, principal localidad de esta industria, empleaban menos de 15 obreros $^{21}$. La emergencia de algunas grandes empresas, especialmente desde $1880^{22}$, no impidió la supervivencia de las pequeñas y medianas unidades productivas, e incluso de la actividad puramente domiciliaria. En 1892 se contabilizaron 734 empresas en la provincia de Girona, con 10229 trabajadores, lo que arroja una media de solo 14 trabajadores por empresa ${ }^{23}$. Estas empresas de diversos tamaños mantenían estrechas relaciones horizontales ${ }^{24}$, que no solo tenían lugar, como en otros sectores, cuando incrementos no sostenidos de la demanda se resolvían subcontratando las puntas de producción, sino que tenían un carácter más estructural. La heterogeneidad de la materia prima y la extrema diversidad de la gama de tapones implicaban que todas las empresas tuvieran, en uno u otro momento, corcho no apropiado para los tapones que sus clientes demandaban, un corcho que, convertido en cuadrados o tapones, vendían a otras empresas locales. La intensidad de estas transacciones dentro del distrito permitía la existencia de unidades productivas muy pequeñas, que solo vendían en plaza sin acceder directamente a los mercados exteriores, por lo que podían sortear la única barrera de entrada relevante existente en el sector: la capacidad de operar en los entramados del negocio de exportación.

\section{Las empresas analizadas: Coris y Bech de Careda}

El análisis de la irregularidad del trabajo en el sector corchero se abordará a partir de los libros de nóminas semanales de dos empresas en las décadas de 1890 y 1900. La primera, con sede en Llagostera, es la de Francesc Coris Mundet y su yerno Josep Raset, cuyos semanales se analizarán para el período 1891-1910. La segunda es Bech de Careda Hermanos, de Agullana, cuyas nóminas se han conservado para el período 1891-1895 y parcialmente (disponemos del libro de pago a los taponeros, pero no al resto de trabajadores) para el año 1903. La elección de los casos ha sido impuesta por la conservación de los fondos, pero, por sus dimensiones y su base tecnológica, parecen bastante representativos de las medianas empresas del sector. La casa Coris ocupó entre 11 y 43 trabajadores a lo largo del período analizado, mientras que Bech de Careda empleó entre 25 y 75 obreros entre 1891 y 1895 . En ambas, la producción era básicamente manual, aunque en los años analizados se introdujeron máquinas movidas a mano (denominadas de ribot o de garlopa), que se utilizaron solo marginalmente para la producción de tapones de baja calidad. A diferencia de los obradores más pequeños, ambas empresas

\footnotetext{
${ }^{20}$ Datos de Giménez Guited en Sala (1998, p. 113).

${ }^{21}$ Arxiu Municipal de Palafrugell (AMP), Manuscrits i documents solts.

22 Como las de Martí Montaner o de la Veuve Berton, en Palamós, con 700 y 1000 trabajadores respectivamente; la de Tomás Brugada, en Sant Feliu de Guíxols, con unos 300 obreros, o Miquel y Vinke, en Palafrugell, con unos 500 operarios en 1904 y unos 1000 en 1907 (Sala, 1998, pp.117-118; Sala, 2003; Artigas, 1907, pp. 280, 283 y 285).

${ }^{23}$ Vila Saglietti (1892, p. 68).

${ }^{24}$ Ejemplos en Alvarado (2002a, pp. 120-128; Alvarado, 2004, pp. 132-136 y 168-174; 2005, pp. 91-102).
} 
contaban con sucursales en los mercados exteriores. Coris tuvo una filial en Epernay de 1880 a 1903 y en Wiesbaden de 1905 a 1911. El cierre de la delegación en la Champagne, motivado, parece ser, por problemas de mala gestión ${ }^{25}$, y la posterior reorientación hacia el mercado alemán, implicaron cambios importantes en el tipo de producto. Así, mientras entre 1891 y 1901, etapa de máximo auge de la sucursal de Epernay, los tapones de mayor calidad para champán (trefinos y tirajes) representaban el $49 \%$ de la producción de la empresa, entre 1905 y 1910, cuando la empresa vendía principalmente en Alemania, este tipo de tapones se redujo drásticamente al 1,8\% de la producción, en la que dominaban las calidades medio-bajas. Por su parte, Bech de Careda abrió en 1891 una sucursal en Mainz, desde la que atendía el mercado alemán y del resto de la Europa Central y Oriental, y a la que dirigía cerca del $90 \%$ de su producción ${ }^{26}$. Aunque Bech también fabricaba trefinos, su orientación comercial implicaba una especialización en tapones de calidades medio-bajas, que supusieron cerca del 75\% de los producidos en 1891-1895.

Las nóminas de estas empresas dividen a los trabajadores en dos grupos: los taponeros, que cobraban a destajo, sobre los cuales se indica semanalmente el número de tapones elaborados, su calidad, la tarifa pagada por millar y la remuneración final; y todos los demás trabajadores, que cobraban por jornal, para los cuales se especifican el número de jornales semanales trabajados, la remuneración por jornal y el pago total semanal. Las tarifas a jornal y a destajo, que eran algo más bajas en la zona de la frontera y, por tanto, en Bech de Careda, que en el área de las Gavarres donde se localizaba Coris ${ }^{27}$, no variaron a lo largo de todo el periodo en ninguna de las dos empresas, una estabilidad de los salarios nominales que fue característica del período también en otros sectores industriales ${ }^{28}$. Ello permitirá utilizar dichas tarifas como indicador de las jerarquías obreras sin introducir correcciones adicionales. Por otra parte, en el caso de Coris la fuente especifica en ocasiones el oficio de los trabajadores a jornal, en su mayor parte cuadradores, mientras que este dato no aparece nunca en los libros de Bech de Careda. Además, sabemos en todos los casos el género de los trabajadores de Coris, mientras que en el caso de Bech de Careda desconocemos este dato para el $20 \%$ de los obreros del período 1891-1895.

\section{División del trabajo y jerarquías obreras}

La división del trabajo en la manufactura taponera se concretaba en la existencia de distintos oficios especializados. Las fases iniciales del proceso productivo, consistentes en hervir, toscar y raspar el corcho, eran realizadas por trabajadores masculinos que frecuentemente no tenían una relación exclu-

\footnotetext{
25 Alvarado (2004, pp. 143-191).

${ }^{26}$ Alvarado (2002a, pp. 162-166)

${ }^{27}$ Aunque no siempre existe la seguridad de que las calidades trabajadas sean idénticas, lo sugiere el hecho de que los trefinos se pagaran entre 5 y 5,5 pesetas el millar en Bech de Careda, y entre 5 y 6,5 pesetas en Coris, aunque los tirajes se remuneraban igual ( 3,5 pesetas millar) en ambas empresas.

${ }^{28}$ Las series sobre el textil en Cataluña, por ejemplo, muestran una gran estabilidad de los salarios nominales en la década de 1890. A partir de 1900 hubo aumentos salariales en algunas empresas, pero distaron de ser generales (Llonch, 2004; Camps, 1995; Enrech, 2005).
}

siva con una empresa. En Coris, muchos de estos trabajadores eran ocasionales, pero incluso los que mantenían una relación más continuada con la empresa trabajaban en ella un reducido número de días a la semana y seguramente se ocupaban en otras fábricas el resto de jornadas. En Bech de Careda el trabajo de estos obreros era más estable, aunque muchos de ellos tampoco solían trabajar la semana completa. El reducido número de jornales dedicados a estas operaciones podría deberse parcialmente al hecho de que una parte del corcho utilizado fuera comprado ya preparado, una hipótesis que es especialmente plausible cuando se trataba de materia prima procedente del suroeste peninsular, donde existían gran número de empresas dedicadas a tareas preparadoras.

Después de estas operaciones, tenían lugar las fases centrales del proceso productivo: cuadrar y hacer los tapones. Cuadrar, es decir, cortar cuadradillos de corcho con la anchura que tendría luego el tapón, era una tarea efectuada por trabajadores masculinos cualificados, que exigía del trabajador un conocimiento de la materia prima que permitiera extraer de cada plancha de corcho el producto más valorado en el mercado. La operación de cortar las aristas de los cuadrados hasta convertirlos en tapones, que constituía el oficio de taponero propiamente dicho, requería otro tipo de habilidad: la pericia manual para producir tapones con rapidez y perfección. No obstante, el nivel de cualificación de los taponeros y su remuneración variaba enormemente, como veremos, según la calidad de los tapones producidos. Finalmente, las últimas operaciones a las que eran sometidos los tapones, escoger y contar, eran consideradas menos cualificadas, aunque también existían diferencias relevantes en la remuneración de los escogedores según la calidad de los tapones. En la empresa Coris estas últimas eran tareas realizadas principalmente (pero no exclusivamente) por hombres, mientras que en Bech de Careda esta operación empleaba sobre todo a mujeres.

La división del trabajo que imperaba en las empresas estudiadas iba mucho más allá de la especialización en las ocupaciones que acabamos de describir, porque dentro de los principales oficios, el de taponero y el de cuadrador, existían unas estrictas pautas de especialización. En primer lugar, por razón de género. Entre los taponeros, tal como puede observarse en la tabla 1 (Apéndice), las mujeres tenían un papel preeminente en la producción de tapones de calidades bajas, especialmente en los tapones a máquina (los que se remuneraban a menos de 1 peseta el millar), pero también en los tapones a mano de calidades más bajas (por debajo de las 1,5 o 2 pesetas el millar). La presencia de las mujeres continuaba existiendo, aunque de forma minoritaria, en la producción de tapones de calidades intermedias, de entre 2 y 3 pesetas, para la elaboración de los cuales cobraban idénticas tarifas a destajo que los hombres. Por último, los tapones destinados a champán eran productos reservados a los hombres.

También existía una nítida división sexual del trabajo en las ocupaciones a jornal. Las mujeres estaban excluidas del oficio de cuadrador y las que trabajaban a jornal lo hacían principalmente como escogedoras, además de otras tareas más ocasionales. Las tarifas por jornal de las mujeres oscilaban entre las 0,75 y las 1,5 pesetas en Bech de Careda y entre las 0,5 y las 2 pesetas en Coris (donde apenas había mujeres jornaleras), mientras que los jornales de los hombres, que solo en el caso de los aprendices eran inferiores a las 2 pesetas, podían llegar, en Bech de Careda, a las 3,5 pesetas (con algún jornal ocasional 
de 4 o 5 pesetas) y en Coris a las 4,5 pesetas, lo que situaba a estos trabajadores, probablemente cuadradores de trefinos ${ }^{29}$, en la banda alta de las retribuciones de la industria catalana ${ }^{30}$. En Bech de Careda existía, además, un puesto de trabajo remunerado por semanas, independientemente de los jornales trabajados, probablemente correspondiente a un encargado, que cobraba de 27 a 30 pesetas semanales.

Además de la especialización productiva según género, la división del trabajo según calidades era también muy marcada. En ambas empresas los taponeros de trefinos solo producían este tipo de tapones (cuya tarifa oscilaba entre las 5 y las 6,5 pesetas por millar) o, a lo sumo, tapones de tiraje a 3,5 pesetas millar. Entre 1891 y 1901, cuando una parte muy significativa de la producción de Coris consistía en tapones para champán, los obreros que producían esta calidad no elaboraban tapones inferiores, incluso en aquellas semanas en que no había trabajo suficiente de trefinos para todos ellos e incluso si simultáneamente la empresa necesitaba contratar nuevos trabajadores para elaborar tapones de calidades más bajas. A partir de noviembre de 1901, la fabricación de trefinos se paralizó, debido a los problemas de la sucursal de Epernay, y solo se reinició de forma muy secundaria y ocasional a partir 1904. Estos cambios en el tipo de producto, que se explican por la reorientación antes mencionada de la empresa hacia el mercado centroeuropeo, consumidor de pocos tapones para vinos espumosos, implicaron el despido de todos los taponeros de trefinos. Solo algunos de ellos volvieron a la empresa al cabo de algunos años para producir tapones de calidades más bajas y, ocasionalmente, los pocos trefinos que se producían. Aunque no de forma tan estricta, en ambas empresas los taponeros que elaboraban tapones más baratos solían también centrarse en un modelo concreto. Eran muy raros los casos en los que un trabajador cambiara de tipo de tapón y, cuando ocurría, siempre se daba entre calidades similares. Aunque esta marcada especialización podía convenir en algunos aspectos a los empresarios (reducía los costes de supervisión de la calidad e implicaba que los taponeros de trefinos, sin duda con mayor capacidad de negociación, no podrían incrementar las tarifas de los tapones baratos), respondía probablemente a una fuerte cultura de oficio de los taponeros cualificados.

Las diferencias en jornales o tarifas por millar de tapones de los trabajadores en función de su especialización daban lugar a una escala de ingresos diferenciada, con una jerarquía clara entre los trabajadores más cualificados -los taponeros y cuadradores de trefinos- y el resto de trabajadores masculinos, y entre estos y las mujeres. Trabajando a plena capacidad un taponero de trefinos podía obtener unas 30 pesetas o más semanales, mientras que los cuadradores mejor pagados podían cobrar 27 pesetas a la semana. En cambio, los que elaboraban tapones modelo podían obtener, trabajando a tiempo completo, unos ingresos de entre 20 y 23 pesetas, mientras los que fabricaban las gamas más bajas de tapones a mano (mayoritariamente mujeres que cobraban tarifas de entre 1 y 1,75 pesetas el millar) podrían ingresar, trabajando toda la semana, entre 9 y 15 pesetas. No obstante, el hecho de que, como veremos en el próximo apartado, era frecuente

\footnotetext{
${ }^{29}$ Los cuadradores más cualificados cobraban estos jornales según Roger (1911, pp. 106-107).

${ }^{30}$ Maluquer de Motes y Llonch (2005, p. 1176).
}

que los obreros no trabajaran a plena capacidad implicaba que los ingresos semanales fluctuaran extraordinariamente y que, tal como indican los gráficos siguientes, en la mayoría de semanas los trabajadores, especialmente los que iban a destajo, ingresaran bastante menos que si hubieran trabajado a tiempo completo.

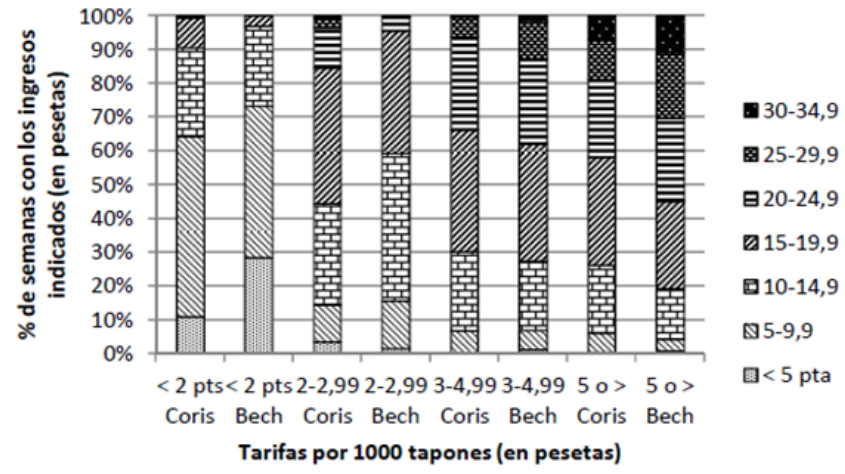

Gráfico 1. Porcentaje de semanas trabajadas según ingreso semanal y tarifas por millar de tapones (hombres).

Fuente: ver tabla 1 (Apéndice).

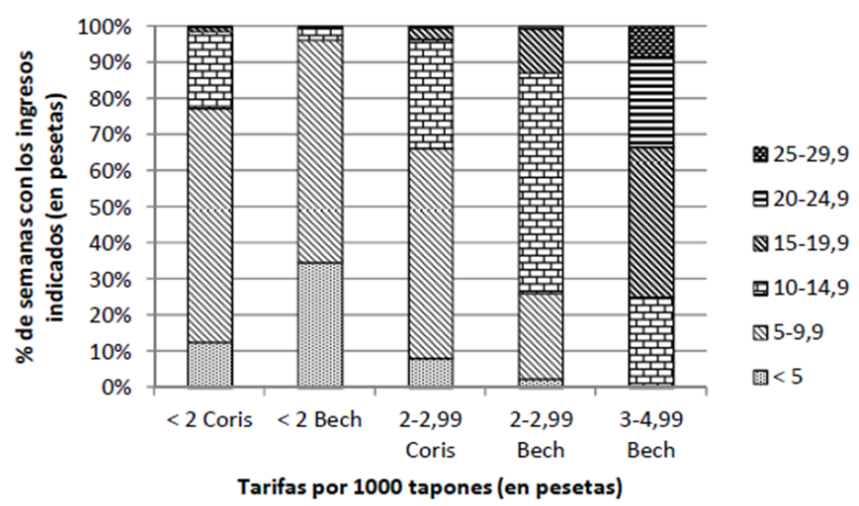

Gráfico 2. Porcentaje de semanas trabajadas según ingreso semanal y tarifas por millar de tapones (mujeres).

Fuente: ver tabla 1 (Apéndice).

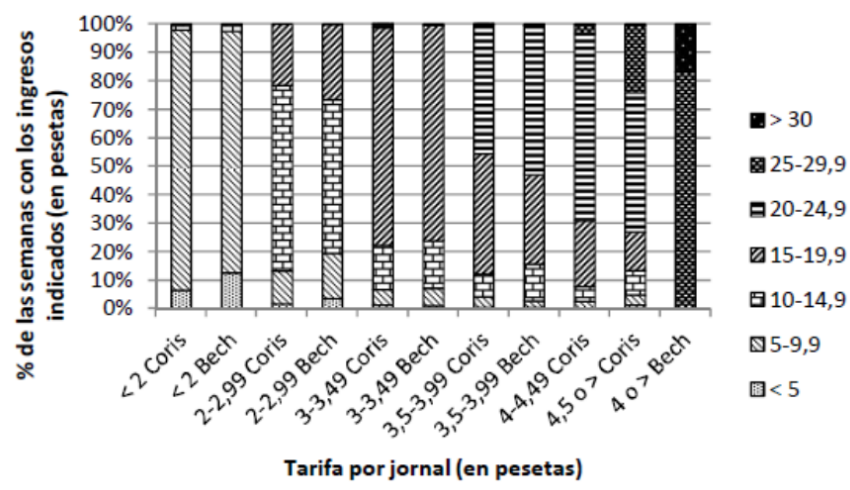

Gráfico 3. Porcentaje de semanas trabajadas según ingreso semanal y jornal (hombres)*.

* En Coris se excluyen hervidores, toscadores y otro personal con trabajos eventuales; en Bech, se excluye al encargado, que cobraba por semanas.

Fuente: ver tabla 1 (Apéndice). 


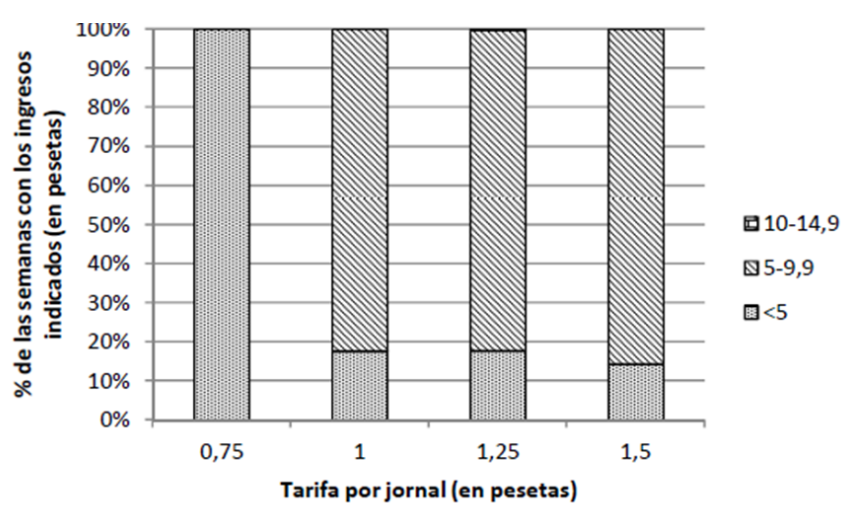

Gráfico 4. Porcentaje de semanas trabajadas según ingreso semanal y jornal (mujeres, Bech de Careda).

Fuente: ver tabla 1 (Apéndice).

\section{Rotación e irregularidad del trabajo}

La estricta especialización que hemos visto en el apartado anterior tenía lugar en el contexto de una fuerte irregularidad en el trabajo. La figura 5 muestra las notables variaciones en las dimensiones de las plantillas que tuvieron lugar en el período estudiado. Además, existía una elevada tasa de rotación por cada puesto de trabajo (la media anual era del 135\% en Coris y del 161\% en Bech de Careda ${ }^{31}$ ). Estas cifras estaban influidas por la existencia de algunas operaciones -hervir, toscar, raspar-, que se realizaban en buena medida por personal ocasional, especialmente en Coris. Pero incluso si prescindimos de este tipo de trabajadores, la tasa de rotación continuaba siendo muy alta: del 95\% en Coris y del 159\% en Bech de Careda en el caso de los hombres taponeros. Por otra parte, la tasa de rotación de las mujeres (del 125\% entre las taponeras de Coris y del 170\% entre las de Bech de Careda) era sustancialmente más elevada que la de los hombres ${ }^{32}$.

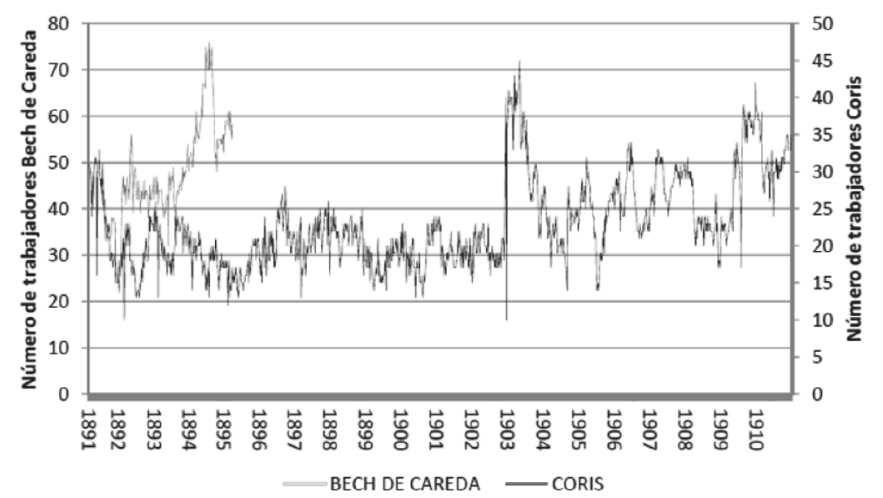

Gráfico 5. Evolución del número de trabajadores en las empresas Coris y Bech de Careda, 1891-1910.

Fuente: ver tabla 1 (Apéndice).

\footnotetext{
${ }^{31}$ La tasa de rotación se refiere al porcentaje de abandonos del puesto de trabajo respecto al número medio de trabajadores empleados. Cuando un mismo trabajador entra y sale de la plantilla de la empresa, se han considerado solo aquellos casos en los que el período sin trabajar es, como mínimo, de un mes.

${ }^{32}$ Esta tasa era de cerca del $100 \%$ entre los hilanderos de Manchester en 1800, del $75 \%$ en las empresas de construcción de máquinas alsacianas de 1820-1830 (Brown y Neumeier, 2001, p. 189) y del $123 \%$ en la industria americana de 1920 (Owen, 1995, p. 822).
}

Esta elevada tasa de rotación era el resultado de la coexistencia de un núcleo muy reducido de trabajadores con larga continuidad en la empresa (algunos de los cuales, no obstante, entraron y salieron en más de una ocasión de la plantilla) y una mayoría muy móvil, formada por obreros que trabajaron pocas semanas en las empresas consideradas. La tabla 2 (Apéndice) muestra que en el caso de Coris una mayoría muy notable de trabajadores estuvieron en la empresa menos de 40 semanas (de las 1034 que registra la fuente), y un porcentaje muy importante (la mitad de los trabajadores a jornal, en torno a un tercio de los taponeros a destajo) trabajaron menos de 10 semanas. Dichos porcentajes son de un orden de magnitud similar en Bech de Careda. En el otro extremo de la distribución, en Coris solo el 1,7\% de los trabajadores a jornal, el 2,2\% de los taponeros y el 1,6\% de las taponeras permanecieron en la empresa 500 semanas o más. En general, la tabla también muestra que las diferencias según género en relación con las semanas trabajadas eran poco importantes en ambas empresas.

También las jornadas de trabajo dentro de cada semana eran notablemente irregulares, tal como indica la tabla 3 (Apéndice). En Coris existe información sobre el tipo de ocupación de los trabajadores a jornal, por lo que se distinguen los obreros con trabajos que daban lugar a jornales ocasionales, como los hervidores o toscadores. Por otra parte, es necesario precisar que, aunque las fuentes de estas empresas no nos dicen nada sobre la duración, en horas, de la jornada de trabajo, podemos considerar que el jornal estándar constaba de 10 horas a inicios de siglo xx y, tal vez, 10,5 en la década de $1890^{33}$.

Como podemos observar, el trabajo irregular era especialmente marcado entre los trabajadores de Coris. En solo el $14,5 \%$ de las semanas se trabajaron las 6 jornadas (muy ocasionalmente con alguna fracción adicional) que constituían la semana laboral estándar de la época. La moda se situaba entre las 5 y las 5,75 jornadas, pero en cerca del $39 \%$ de las semanas se trabajaron menos de 5 jornales. Incluso si excluimos a los trabajadores con ocupaciones habitualmente ocasionales en las fábricas, la irregularidad continúa siendo relevante, ya que solo el $16,4 \%$ de las semanas trabajadas constan de los 6 jornales completos, mientras que las que no llegan a los 5 jornales suman el $29 \%$.

En Bech de Careda, donde cerca de la mitad de las semanas trabajadas contaron con 6 jornales, la irregularidad del trabajo era mucho menor, incluso teniendo en cuenta que, en el caso de los hombres, no hemos podido separar los hervidores y toscadores de los trabajadores masculinos que a priori tenían un empleo más regular, como es el caso de los cuadradores. Por otra parte, es importante señalar que en Bech de Careda, donde a diferencia de Coris trabajaban habitualmente jornaleras (probablemente escogedoras), no existían significativas diferencias según género en el número de jornales trabajados por semana.

Por lo que respecta a los taponeros destajistas, la tabla 4 (Apéndice) muestra, para el caso de la fabricación a mano, el porcentaje de semanas trabajadas según la cantidad de tapones producidos, expresados en relación a un máximo técnico de 9000 tapones semanales. Dicho máximo deriva de conside-

\footnotetext{
33 Según Roger, en 1911 ya hacía tiempo que la jornada era de 10 horas, aunque en "tiempos lejanos" se trabajaban 10,5. Roger (1911, pp. 40-42 y 61-62). El reglamento interior de la empresa Torres Jonama, de Palafrugell, fijaba en 1912 una jornada de 10 horas. AMP, Junta Local de Reformas Sociales.
} 
rar que un taponero manual podía producir entre 1000 y 1500 tapones diarios, lo que suponía, en una semana completa de 6 días laborables, entre 6000 y 9000 tapones $^{34}$. Existían, no obstante, diferencias en el número de tapones diarios que era posible producir según la calidad de los mismos. Los taponeros de trefinos casi nunca produjeron más de 8000 tapones semanales (y pocas veces más de 7000) tanto en Coris como en Bech de Careda, mientras que era mucho más frecuente que los que producían modelos u otras calidades medias o bajas superaran los 7000 u 8000 tapones semanales.

La tabla indica que en aproximadamente la mitad de las semanas trabajadas en ambas empresas el número de tapones por trabajador no superaba el índice 60, es decir, los 5400 tapones semanales, que podemos considerar el umbral mínimo del trabajo a tiempo completo. Las diferencias según género eran poco marcadas. En Bech de Careda, entre 1891 y 1895 , el porcentaje de las semanas trabajadas que no llegaba a dicho umbral era del $52 \%$ en ambos sexos, mientras que en 1903 era del $46 \%$ en el caso de los hombres y el $63 \%$ en el de las mujeres. Estos porcentajes se asemejaban a los de la empresa Coris, que eran del $48 \%$ en los hombres y del $60 \%$ en las mujeres.

Al ser una producción manual que dependía crucialmente de las habilidades de cada trabajador, es pertinente la hipótesis de que las diferencias en los tapones producidos por semana pudieran derivar del distinto grado de rapidez de los operarios y no de diferencias en su tiempo de trabajo. Para contrastar esta idea hemos analizado (tabla 5, Apéndice) la producción semanal de cada taponero en relación con su propio máximo. La tabla vuelve a subrayar la inestabilidad del trabajo de los taponeros, tanto hombres como mujeres, y sugiere que la diversidad en los niveles de producción semanal no era debida principalmente a los distintos grados de habilidad de los trabajadores. En el caso de Coris, solo en un $15 \%$ de las semanas trabajadas por hombres y en cerca de un $9 \%$ de las trabajadas por mujeres, el obrero produjo cerca de su propio máximo, es decir, a un $80 \%$ de este o más. En Bech de Careda, las cifras relativas a los hombres eran, en el período 1891-1895, muy parecidas a las de Coris, mientras que entre las mujeres era más frecuente, aunque también muy minoritaria, una producción cercana a la plena capacidad. En 1903 la irregularidad en el trabajo en la misma empresa parece haberse reducido significativamente (aunque ello puede deberse en parte a una ilusión estadística dado que aquí consideramos un período mucho más breve, de solo 10 meses), pero incluso así continuaba manteniéndose a niveles notables. Es importante señalar que, como ya habíamos subrayado en el caso de los trabajadores a jornal, las diferencias entre hombres y mujeres no son muy significativas y, además, no siempre se presentan en un sentido coincidente, porque mientras en Coris las mujeres trabajaban menos semanas a plena capacidad que los varones, en Bech de Careda sucedía lo contrario.

La mecanización parcial a través de máquinas de garlopa no introdujo cambios relevantes en la irregularidad del trabajo. La producción de tapones a máquina era en ambas empresas muy fluctuante y podían dejarse de producir durante semanas. También experimentaba fuertes variaciones el trabajo de cada una de las taponeras a máquina. Considerando que la produc-

\footnotetext{
${ }^{34}$ Espadalé (2002, p. 80).
}

ción a plena capacidad se situaba en unos 18000 tapones a la semana ${ }^{35}$, en Coris solo en un tercio de las semanas trabajadas se alcanzó este umbral, mientras que en Bech de Careda la única taponera a máquina solo llegó a esta cantidad en 3 semanas de las 117 en que trabajó.

Otra hipótesis que conviene contrastar es hasta qué punto los niveles de cualificación daban lugar a diferentes pautas de trabajo de los taponeros. Para ello, desglosaremos los datos de la tabla 5 (Apéndice) referidos a los hombres según la calidad de tapones producidos (tabla 6, Apéndice) ${ }^{36}$. En Coris, los trabajadores más cualificados, que producían las calidades superiores, eran justamente los que tendían a trabajar con mayor irregularidad. Solo en el $25 \%$ de las semanas trabajadas por taponeros de trefinos (tarifas de 5 pesetas o más el millar) la producción del trabajador alcanzó por lo menos el $60 \%$ de su propio máximo. Este porcentaje era similar entre los taponeros que producían tirajes y trefinos pequeños (de 3,5 a 5 pesetas), pero era mucho más alto entre los más regulares taponeros de calidades inferiores, quienes entre el $55 \%$ y el $70 \%$ de las semanas produjeron al $60 \%$ de su máximo o más. El hecho de que justamente los taponeros mejor pagados fueran también los que acumulaban más semanas trabajando por debajo de la plena capacidad sugiere la existencia de comportamientos de "preferencia por el ocio" o de una oferta de trabajo "con pendiente hacia atrás», que con frecuencia se han considerado típicos de los trabajadores preindustriales y que la bibliografía sobre el sector corchero ha destacado repetidamente ${ }^{37}$.

Aunque la gradación no es tan clara, algo parecido sucede en Bech de Careda entre 1891 y 1895, donde los taponeros de trefinos solo trabajaron un $22 \%$ de las semanas a por lo menos el $60 \%$ de su máximo, mientras que en el resto de colectivos este porcentaje aumentaba, como mínimo, a más del $40 \%$. No obstante, en la misma empresa en 1903, cuando el trabajo se había regularizado significativamente, existían menos diferencias entre obreros con distintas especializaciones.

\section{6. ¿Por qué era el trabajo tan irregular?}

La fluctuante demanda de fuerza de trabajo por parte de las empresas generaba, sin duda, una parte relevante de la irregularidad del trabajo, aunque no la explica completamente porque existe solo una débil correlación entre el número total de tapones producidos semanalmente y los fabricados por cada trabajador. La estacionalidad no parece ser relevante ${ }^{38}$, pero el negocio de exportación estaba sometido a numerosas fluctuaciones debidas a las oscilaciones de la demanda internacional de tapones, a la presión de la competencia, a las posibles dificultades financieras o comerciales de los clientes y a la capacidad de las empresas catalanas de gestionar adecuadamente sus redes comerciales en el extranjero ${ }^{39}$.

\footnotetext{
${ }^{35}$ Espadalé (2002, p. 80).

${ }^{36}$ No presentamos este ejercicio para las mujeres porque en su caso el abanico de calidades producidas es muy restringido.

${ }^{37}$ Rule (1981, pp. 52-57); Roger (1911).

${ }^{38}$ Los índices de variaciones estacionales de los tapones fabricados y de los jornales se mueven en un abanico muy estrecho, de entre 90 y 109.

39 Diversas monografías empresariales dan cuenta de ello: Alvarado (2004); Ros y Sala (2014); Sala (2003).
} 
La correspondencia de la empresa Coris muestra cómo las oscilaciones en las ventas debidas a todo este conjunto de factores se traducían frecuentemente en despidos, lo que contribuye a explicar la elevada rotación de la fuerza de trabajo. El 31 de enero de 1908 Francesc Coris escribe a Pareras, Sastre y Coris de Wiesbaden que, a tenor de lo que le decían en su última carta sobre los pedidos, «mañana despediré nuevamente a los escogedores que había dado trabajo últimamente». El 21 de marzo del mismo año anunciaba que, dado que la filial de Wiesbaden le había comunicado que no mandara más tapones modelo hasta nueva orden, «de momento hoy he despedido algún trabajador más». Este tipo de gestión de la fuerza de trabajo, sin cortapisas al despido, era habitual y también se aplicó en ocasiones por cuestiones disciplinarias. Por ejemplo, el 3 de abril de 1903 se anotaba al lado del nombre de dos trabajadores la palabra "revoltoso», y estos dos trabajadores dejaron de estar contratados a partir de la semana siguiente.

La organización de la manufactura corchera bajo la forma del distrito industrial favorecía también esta elevada rotación de la fuerza de trabajo. En la línea de lo que ha señalado la mayor parte de la bibliografía sobre los distritos del siglo xx, la concentración de trabajadores con habilidades específicas del sector reducía el coste que para los empresarios tenía la selección y contratación de personal ${ }^{40}$. Desde el punto de vista de los trabajadores, la concentración de la manufactura corchera en localidades próximas y económicamente muy interrelacionadas debía implicar que la información sobre las oportunidades de ocupación circulase con fluidez, favoreciendo los cambios voluntarios de puesto de trabajo. Nuestras fuentes no nos dicen nada sobre el destino de los obreros que abandonaron las empresas estudiadas, pero la importancia de las migraciones de muy corta distancia entre localidades del distrito sugiere que este fenómeno pudo tener una relevancia apreciable ${ }^{41}$.

Por otra parte, las intensas relaciones entre empresas en el seno del distrito ofrecían oportunidades de producir por cuenta propia a domicilio, una actividad que podía ser, en algunos casos, la antesala de la creación de una nueva empresa, aunque con frecuencia no estaba exenta de explotación porque, como afirmaba Roger, las empresas de cierta importancia solían imponer precios muy bajos a estos pequeños productores $^{42}$. Según los libros de contabilidad, Coris compraba habitualmente tapones o cuadrados a otras empresas y entre sus proveedores hemos podido identificar a 12 de sus trabajadores o extrabajadores, algunos de los cuales los encontramos también vendiendo a otras casas, como la gran empresa Martí Montaner, de Palamós ${ }^{43}$. En su mayoría se trata de obreros que trabajaron para Coris en algún momento de su vida y que ejercían por cuenta propia algunos años después. En algún caso fundaron empresas de cierta entidad, pero lo más común es que se tratara de pequeños talleres

\footnotetext{
${ }^{40}$ Aunque este es el punto de vista predominante, algunos autores han sostenido que la abundancia de trabajadores cualificados y la calidad de la información que circulaba en el distrito tendían a conseguir un más eficiente y rápido matching entre trabajador y empresa, reduciendo así la rotación laboral. Un estado de la cuestión en De Blasio y Di Addario (2005).

${ }^{41}$ Alvarado (2002b).

42 Roger (1911, p. 194).

${ }^{43}$ Las compras de Montaner en Llagostera en Alvarado (2004, pp. $200-$ 203).
}

domiciliarios que siempre trabajaron en el sector informal para empresas de mayores dimensiones ${ }^{44}$. Es probable, además, que en algunos casos trabajar por cuenta propia y por cuenta ajena no fueran ocupaciones consecutivas en la vida laboral de los individuos, sino simultáneas. De hecho, 4 de los 12 trabajadores de Coris que vendieron cuadrados o tapones a la misma empresa lo hicieron mientras estaban trabajando para ella como asalariados. Que todo ello era común lo ratifican no solo los observadores de la época, que hablaban de la ubicuidad de los talleres domiciliarios, sino que también lo sugieren otras fuentes. Por ejemplo, en el contexto de la fuerte conflictividad de los años posteriores a la Primera Guerra Mundial, los patronos de la Cassà de la Selva, localidad contigua a Llagostera, acordaron en julio de 1920 que todo individuo que trabajase por cuenta propia con interrupciones inferiores a 12 meses fuera considerado exclusivamente como patrono y no pudiera estar afiliado a ningún sindicato, como tampoco podrían estarlo sus mujeres e hijos. Todo ello, tal como comentaba El Programa, órgano Federal del Bajo Ampurdán, atacaba directamente a los que el mismo periódico calificaba como "patronos obreros» ${ }^{45}$.

Por otro lado sabemos muy poco acerca del grado en que los trabajadores corcheros compatibilizaban su trabajo manufacturero con otras actividades, singularmente la agricultura. Solo alrededor del $10 \%$ de los trabajadores varones de Coris poseían alguna parcela de tierra, de acuerdo con los listados de la contribución rústica, y la mayoría de los que tenían tierras contribuían por cantidades exiguas. Ello sugiere que el trabajo agrario debía de tener escasa relevancia en sus economías familiares, aunque desconocemos la medida en que estos trabajadores podían arrendar parcelas o trabajar ocasionalmente a jornal en actividades agrícolas o forestales.

Algunos de los fenómenos que acabamos de describir -las oscilaciones de la producción de las empresas, las posibilidades que los obreros tenían de simultanear trabajo por cuenta ajena y por cuenta propia- explican probablemente no solo el elevado grado de rotación de los trabajadores, sino también buena parte de la irregularidad de los tiempos trabajo en las semanas en las que estos trabajadores estaban empleados. No obstante, en relación a esto último, debemos tener en cuenta también las características de los tiempos de ocio. Una primera cuestión concerniente a este tema es la incidencia de los festivos. Para cuantificarlos he tomado como referencia para cada semana dos parámetros: la media de jornales trabajados y el número de jornales del obrero que más días trabajó. Los festivos anuales ( mingos) oscilaban entre los 17 y los 20 según los años en Bech de Careda, y entre 15 y 25 en Coris. Ello implica un número máximo de días de trabajo al año de entre 298 y 288 , lo que es coherente, no solo con lo que indicaba Martí Roger para la industria corchotaponera ${ }^{46}$, sino también con el número de jornadas de precepto reguladas por la Iglesia (aunque, como veremos, los días en que se holgaba no eran siempre festivos religiosos) y con el número de jornadas trabajadas al año en la industria textil según el Instituto de

\footnotetext{
${ }^{44}$ Lo indica el hecho de que sus nombres no aparezcan en las matrículas industriales publicadas por Alvarado (2004, pp. 195-200).

45 El Programa, 24-7-1920, p.2.

${ }^{46}$ Roger (1911, pp. 107-115) computa 290 días anuales para los hombres.
} 
Reformas Sociales ${ }^{47}$. En Coris se aprecia una gran sincronía entre los obreros en la observancia de las fiestas, mientras que en Bech de Careda hay más diferencias entre ellos en relación con esta cuestión. Algunos días del calendario religioso (la Candelera, el Lunes de Pascua, San Jaime, la Asunción, Todos los Santos, la Inmaculada) aparecen como festivos en ambas empresas. Otros (San Pedro, San Juan) no eran festivos fijos, aunque era frecuente que algunos trabajadores holgaran total o parcialmente en estas jornadas. Todas las fiestas navideñas, de Navidad a Reyes, implicaban de 2 a 4 días festivos según los años. Las dos fiestas anuales de los patronos locales implicaban en conjunto unos 4 días no laborables. Semana Santa (dejando aparte el Lunes de Pascua, que era siempre festivo) no era una fecha especialmente señalada: en Llagostera se solía hacer menos de un día de fiesta, mientras que en Agullana se celebraban entre 0,5 y 1,5 jornales festivos. Una de las diferencias más relevantes entre ambas empresas se refiere al Carnaval. En Llagostera, esta era sin duda la mayor celebración del año, ya que se holgaban tres días. Por el contrario, en Agullana la mayoría de obreros solo dejaban de trabajar medio jornal. En cambio, en este último pueblo tenía gran relevancia la fiesta de la sociedad recreativa y de socorros mutuos La Concordia, que implicaba dejar de trabajar entre 2 y 3 días según los años.

No obstante, los festivos no explican completamente el número de días holgados. Considerando exclusivamente aquellos 119 obreros a jornal de ambas empresas que trabajaron por lo menos 50 semanas de un año, en el $85 \%$ de los casos los domingos y los festivos que acabamos de describir, computados en un máximo de 25 días, no explican completamente el número de jornales en los que no se trabajó. Con frecuencia la diferencia es notable, ya que en 40 casos el número de días no trabajados más allá de estos festivos "estándar» supera los 20. Entre estos días «no explicados» hay, probablemente, una parte de tiempo dedicado al trabajo a domicilio, pero también a unas pautas tradicionales de ocio que subrayaron todos los observadores de la época. Roger, por ejemplo, no solo señalaba la ubicuidad de San Lunes (aunque afirmaba que estaba en declive en el primer decenio del siglo xx coincidiendo con la emergencia de grandes empresas mecanizadas), sino también la compatibilización del trabajo con el ocio en el taller (canto, conversación, lectura de periódicos, discusiones sobre política) y las interrupciones discrecionales del trabajo «unas veces por la llegada de una embarcación, otras para contemplar, en día de temporal, cómo las olas batían las peñas [...], para presenciar disputas de mujeres o peleas de hombres, o cuando menos para tomar el sol si hacía un día espléndido» ${ }^{48}$. Nuestras fuentes permiten estudiar la incidencia de una de las manifestaciones de estas pautas de ocio, la celebración de San Lunes, para el caso de la empresa Coris. Entre sus fondos, se han conservado, para 11 semanas de febrero a mayo de 1909, unos listados con los días concretos en los que trabajaron los obreros a jornal. La tabla 7 (Apéndice) muestra el promedio de jornales trabajados por obrero en estas 11 semanas y en las 7 sin días festivos. Aunque el número de observaciones es muy limitado, los datos parecen indicar claramente que todavía en

\footnotetext{
${ }^{47}$ El número de fiestas religiosas implicaba un año de trabajo teórico de unos 296 días entre 1868 y 1911. García-Zúñiga (2011, pp. 19 y 31). El IRS (1914) computaba 291 jornadas en la industria textil en 1914.

48 Roger (1911, pp. 36-37). Traducido del catalán.
}

1909 la práctica del San Lunes, que en aquel momento consistía con más frecuencia en trabajar media jornada que no en no trabajar en absoluto, continuaba manteniendo cierta vigencia.

\section{Conclusiones}

Dentro del amplio abanico de pautas laborales en la industria del siglo xix, la manufactura corchera se caracterizaba por una acusada rotación de la fuerza de trabajo, así como por una elevada irregularidad de los días trabajados y de los tiempos de trabajo, especialmente entre los taponeros destajistas. A diferencia de lo que ocurría en otros sectores, todo ello no era solo propio de las mujeres u otros colectivos que trabajaban en el segmento secundario del mercado de trabajo, sino que la irregularidad era incluso más importante entre los trabajadores masculinos más cualificados.

Distintos factores contribuyen a explicar estas pautas laborales. En la etapa estudiada en este artículo, la industria taponera era un sector particularmente expuesto a la competencia internacional. No obstante, antes de la Primera Guerra Mundial, la respuesta a la presión de la competencia sobre los costes no fue todavía, por lo menos en las pequeñas y medianas empresas, la mecanización masiva aparejada a una creciente feminización del trabajo que dominó a partir de 1918. No lo fue por razones técnicas, pero tampoco, probablemente, por la fuerza de la cultura de oficio entre los trabajadores más cualificados. En cambio, las empresas trataban de mantener la competitividad basándose en una gestión muy flexible de la mano de obra (tanto por lo que respecta al número de trabajadores como al número de jornadas semanales que estos trabajaban) y a una estricta división del trabajo que, a la vez que respetaba las jerarquías de oficio, debía de incrementar la productividad. De forma similar a lo que han argumentado la mayoría de autores que han analizado los distritos industriales del siglo xx, una estrategia empresarial de este tipo se veía facilitada por la concentración territorial de la manufactura, que implicaba para las empresas la existencia de una amplia oferta de trabajo con las cualificaciones específicas requeridas y, para los trabajadores, la posibilidad de encontrar empleo alternativo (excepto en momentos de crisis general del sector) o, en un contexto en el que la tecnología permitía la fabricación doméstica y las empresas del distrito recurrían frecuentemente a la subcontratación, de producir por su cuenta de forma más o menos ocasional. El ejemplo de la industria taponera constituye pues un buen observatorio para el análisis del conjunto de factores que incidían en la configuración de sistemas tecno-laborales concretos, con distintas implicaciones sobre la rotación de trabajadores y la irregularidad del trabajo. Junto a la tecnología y las tradiciones de oficio, señala la necesidad de prestar atención al tipo de mercados y, especialmente, a las interrelaciones, no exentas de conflicto, entre empresas y trabajadores que se establecían en los distritos industriales.

\section{Financiación}

El presente trabajo ha sido financiado por el Ministerio de Economía, Industria y Competitividad (proyecto HAR201454891-P). 


\section{Apéndice}

\section{Tabla 1}

Especialización de los taponeros según género y tipo de tapones producidos

\begin{tabular}{lcccccr}
\hline Tipo de tapones & \multicolumn{2}{c}{ Coris, 1891-1910 } & \multicolumn{2}{c}{ Bech de Careda, 1891-1895 * } & \multicolumn{2}{c}{ Bech de Careda, 1903 } \\
\hline $\begin{array}{l}\text { Tarifas destajo } \\
\text { (ptas/millar tapones) }\end{array}$ & \% Hombres & \% Mujeres & \% Hombres & \% Mujeres & \% Hombres & \% Mujeres \\
\hline $0,3-0,9$ & 0,3 & 99,7 & 0,0 & 99,2 & 0,0 & 0,0 \\
\hline $1-1,4$ & 8,6 & 91,4 & 13,8 & 30,9 & 0,0 & 0,0 \\
\hline $1,5-1,9$ & 31,1 & 68,9 & 41,7 & 5,1 & 60,0 & 40,0 \\
\hline $2-2,4$ & 89,4 & 10,6 & 83,3 & 14,5 & 65,2 & 34,8 \\
\hline $2,5-2,9$ & 93,0 & 7,0 & 93,3 & 5,8 & 100,0 & 0,0 \\
\hline $3-3,4$ & 100,0 & 0,0 & 95,7 & 4,1 & 100,0 & 0,0 \\
\hline $3,5-3,9$ & 100,0 & 0,0 & 100,0 & 0,0 & 100,0 & 0,0 \\
\hline 4 o más & 100,0 & 0,0 & 100,0 & 0,0 & 100,0 & 0,0 \\
\hline
\end{tabular}

* No se han incluido los trabajadores cuyo género desconocemos.

Fuentes: Arxiu Municipal de Llagostera (AMLl), Fons Coris Raset, Setmanals; Arxiu Municipal de Girona (AMG), Fons Bech de Careda, Setmanals.

Tabla 2

Trabajadores según el número de semanas trabajadas

\begin{tabular}{|c|c|c|c|c|c|c|c|}
\hline \multirow[b]{2}{*}{ Núm. semanas } & \multicolumn{3}{|c|}{ Coris, 1891-1910 (1034 semanas) } & \multicolumn{4}{|c|}{ Bech de Careda, 1891-1895 (195 semanas) * } \\
\hline & $\begin{array}{c}\begin{array}{c}\text { Trabajadores } \\
\text { a jornal (\%) }\end{array} \\
\begin{array}{c}\text { Hombres } \\
\mathbf{n = 1 8 0}\end{array}\end{array}$ & \multicolumn{2}{|c|}{$\begin{array}{l}\text { Trabajadores } \\
\text { a destajo (\%) }\end{array}$} & \multicolumn{2}{|c|}{$\begin{array}{c}\text { Trabajadores } \\
\text { a jornal (\%) }\end{array}$} & \multicolumn{2}{|c|}{$\begin{array}{l}\text { Trabajadores } \\
\text { a destajo (\%) }\end{array}$} \\
\hline$<10$ & 48,8 & 30,4 & 39,7 & 38,9 & 31,5 & 57,1 & 44,5 \\
\hline $10-39$ & 25,9 & 35,5 & 31,7 & 25,6 & 42,1 & 19,0 & 22,2 \\
\hline $80-129$ & 5,2 & 5,8 & 3,2 & 8,9 & 21,1 & 6,0 & 11,1 \\
\hline 130-199 & 5,2 & 8,0 & 4,8 & 14,4 & 0,0 & 7,2 & 11,1 \\
\hline $200-499$ & 7,5 & 5,8 & 6,3 & - & - & - & - \\
\hline$>500$ & 1,7 & 2,2 & 1,6 & - & - & - & - \\
\hline
\end{tabular}

* No se han incluido los trabajadores cuyo género desconocemos.

** No se han tenido en cuenta las 3 mujeres que trabajaron a jornal en Coris, todas las cuales trabajaron menos del $5 \%$ de las semanas.

Fuentes: ver tabla 1. 
Tabla 3

Porcentaje de semanas según el número de jornales trabajados, trabajadores a jornal

\begin{tabular}{lcccr}
\hline & \multicolumn{2}{c}{ Coris, 1891-1910 } & \multicolumn{2}{c}{ Bech de Careda, 1891-1895* } \\
\hline $\begin{array}{l}\text { Núm. } \\
\text { jornales }\end{array}$ & $\begin{array}{c}\text { Hombres } \\
(\mathbf{n = 1 0 1 6 9 )}\end{array}$ & $\begin{array}{c}\text { Hombres (excluyendo hervidores, toscadores } \\
\text { y oficios similares) }(\mathbf{n = 8 3 2 3 )}\end{array}$ & $\begin{array}{c}\text { Hombres } \\
(\mathbf{n = 4 0 1 9 )}\end{array}$ & $\begin{array}{c}\text { Mujeres } \\
(\mathbf{n = 5 7 5})\end{array}$ \\
\hline$<1$ & 1,0 & 0,4 & 0,1 & 0,3 \\
\hline $1-1,75$ & 5,9 & 1,3 & 1,4 & 3,5 \\
\hline $2-2,75$ & 7,7 & 3,3 & 6,3 & 2,4 \\
\hline $3-3,75$ & 7,4 & 6,1 & 12,4 & 7,8 \\
\hline $4-4,75$ & 16,6 & 17,9 & 31,4 & 26,6 \\
\hline $5-5,75$ & 46,9 & 54,6 & 44,9 & 47,5 \\
\hline 6 o más & 14,5 & 16,4 & $\mathbf{1 0 0 , 0}$ & $\mathbf{1 0 0 , 0}$ \\
\hline Total & $\mathbf{1 0 0 , 0}$ & $\mathbf{1 0 0 , 0}$ & & \\
\hline
\end{tabular}

* No se han incluido los trabajadores cuyo género desconocemos.

Fuentes: Ver cuadro 1.

Tabla 4

Porcentaje de semanas según la cantidad de tapones elaborados (9000 = 100)

\begin{tabular}{lcccccc}
\cline { 2 - 8 } & \multicolumn{2}{c}{ Coris (1891-1910) } & \multicolumn{2}{c}{ Bech de Careda (1891-95) } & \multicolumn{2}{c}{ Bech de Careda (1903) } \\
\hline $\begin{array}{l}\text { Tapones elaborados por } \\
\text { semana (9000=100) }\end{array}$ & $\begin{array}{c}\text { Hombres } \\
(\mathbf{n = 9 3 8 4})\end{array}$ & $\begin{array}{c}\text { Mujeres } \\
(\mathbf{n = 3 2 9 4})\end{array}$ & $\begin{array}{c}\text { Hombres } \\
(\mathbf{n = 3 1 6 5 )}\end{array}$ & $\begin{array}{c}\text { Mujeres } \\
(\mathbf{n = 3 9 9 )}\end{array}$ & $\begin{array}{c}\text { Hombres } \\
(\mathbf{n = 9 5 9 )}\end{array}$ & $\begin{array}{c}\text { Mujeres } \\
(\mathbf{n = 2 7 5})\end{array}$ \\
\hline$<20$ & 3,2 & 1,9 & 1,9 & 2,3 & 1,2 & 1,1 \\
\hline $20-39,9$ & 17,3 & 24,5 & 16,2 & 15,0 & 10,0 & 26,2 \\
\hline $40-59,9$ & 27,6 & 33,8 & 34,0 & 34,8 & 35,0 & 36,0 \\
\hline $60-79,9$ & 30,0 & 25,7 & 33,0 & 39,1 & 32,4 & 24,0 \\
\hline $80-99,9$ & 17,0 & 11,7 & 13,3 & 8,3 & 17,6 & 12,7 \\
\hline$>100$ & 4,9 & 2,4 & 1,6 & 0,5 & 3,8 & 0,00 \\
\hline & $\mathbf{1 0 0}$ & $\mathbf{1 0 0}$ & $\mathbf{1 0 0}$ & $\mathbf{1 0 0}$ & $\mathbf{1 0 0}$ & $\mathbf{1 0 0}$ \\
\hline
\end{tabular}

* Sin incluir los trabajadores cuyo género desconocemos.

Fuentes: ver tabla 1.

\section{Tabla 5}

Porcentaje de semanas según la cantidad de tapones elaborados (máximo de cada trabajador $=100$ )

\begin{tabular}{|c|c|c|c|c|c|c|}
\hline \multirow[b]{2}{*}{$\begin{array}{c}\text { Tapones elaborados por } \\
\text { semana (máximo de cada } \\
\text { trabajador=100) }\end{array}$} & \multicolumn{2}{|c|}{ Coris, 1891-1910 } & \multicolumn{2}{|c|}{ Bech de Careda, 1891-1895* } & \multicolumn{2}{|c|}{ Bech de Careda, 1903} \\
\hline & $\begin{array}{l}\text { Hombres } \\
(n=9383)\end{array}$ & $\begin{array}{l}\text { Mujeres } \\
(n=3290)\end{array}$ & $\begin{array}{l}\text { Hombres } \\
(n=3146)\end{array}$ & $\begin{array}{l}\text { Mujeres } \\
(n=398)\end{array}$ & $\begin{array}{c}\text { Hombres } \\
(n=955)\end{array}$ & $\begin{array}{c}\text { Mujeres } \\
(\mathrm{n}=275)\end{array}$ \\
\hline$<20$ & 3,1 & 2,4 & 1,6 & 1,0 & 0,7 & 0,4 \\
\hline $20-39,9$ & 16,1 & 18,0 & 9,8 & 6,5 & 2,0 & 1,4 \\
\hline $40-59,9$ & 31,4 & 40,9 & 35,7 & 22,4 & 11,8 & 17,0 \\
\hline $60-79,9$ & 34,5 & 29,9 & 38,9 & 44,5 & 43,9 & 39,9 \\
\hline $80-100$ & 14,9 & 8,8 & 14,0 & 25,6 & 41,6 & 41,3 \\
\hline Total & 100 & 100 & 100 & 100 & 100 & 100 \\
\hline
\end{tabular}

* Sin incluir los trabajadores cuyo género desconocemos.

Fuentes: ver tabla 1. 


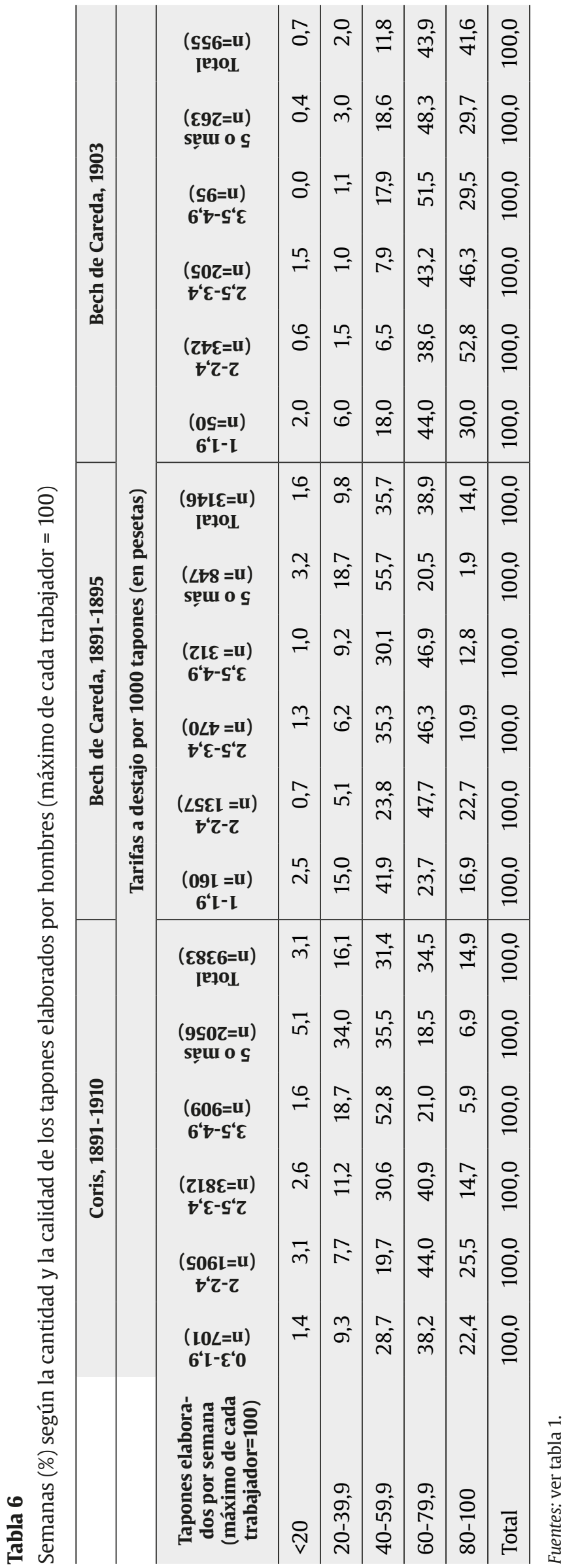


Tabla 7

Jornales por trabajador según el día de la semana, Coris (febrero-mayo de 1909)

\begin{tabular}{lcc}
\cline { 2 - 3 } & 11 semanas & $\begin{array}{c}\text { 7 semanas (eliminando las que } \\
\text { contienen festivos) }\end{array}$ \\
\hline Lunes & 0,5 & 0,6 \\
\hline Martes & 0,8 & 0,9 \\
\hline Miércoles & 0,9 & 0,9 \\
\hline Jueves & 0,8 & 0,8 \\
\hline Viernes & 0,8 & 0,8 \\
\hline Sábado & 0,9 & 0,9 \\
\hline
\end{tabular}

Fuentes: ver tabla 1.

\section{Fuentes}

Arxiu Municipal de Girona. Fondo Bech de Careda.

Arxiu Municipal de Llagostera. Fondo Coris Raset, Contribución rústica.

Arxiu Municipal de Palafrugell. Manuscritos y documentos sueltos, Junta Local de Reformas Sociales.

\section{Bibliografía}

Alvarado, J., 2002a. El negoci del suro a l'Alt Empordà (s. XVIII-XIX). Museu del Suro, Palafrugell.

Alvarado, J., 2002b. Mercado de trabajo y migraciones en el sector corchero catalán (18501930). En: XXII Encontro Associaçao Portuguesa de História Economica e Social, Aveiro.

Alvarado, J., 2004. Suro, carracs i taps. Llagostera, 1753-1934. Ajuntament, Llagostera.

Alvarado, J., 2005. Industrials i tapers. Del segle xviII al xx. Ajuntament, Cassà de la Selva.

Artigas, P., 1907. Alcornocales e industria corchera. Imprenta alemana, Madrid.

Becattini, G. (ed), 1987. Mercato e forze local: il distretto industriale, Il Mulino, Bolonia.

Brown, J. C. and Neumeier, G., 2001. Job tenure and labour market dynamics during high industrialization: the case of Germany before World War I. European Review of Economic History. 5, 189-217.

Camps, E., 1995. La formación del mercado de trabajo industrial en la Cataluña del siglo xIx. Ministerio de Trabajo, Madrid.

Carter, S. B. y Savoca, E., 1990. Labor Mobility and Lengthy Jobs in Nineteenth-Century America. Journal of Economic History. 50 (1), 1-16.

Catalán, J. Miranda, J. A. y Ramon-Muñoz, R. (eds.), 2011. Distritos y clusters en la Europa del sur, LID, Madrid.

De Blasio, G. y Di Addario, S., 2005. Do workers benefit from industrial agglomeration? Journal of Regional Science, 45 (4), 797-827.

De Vries, J., 2009. La revolución industriosa. Crítica, Barcelona.

Doeringer, P. B. y Piore, M. J., 1985. Mercados internos de trabajo y análisis laboral. Ministerio de Trabajo, Madrid.

Enrech, C., 2005. Indústria i ofici. Conflicte social i jerarquies obreres en la Catalunya tèxtil (1881-1923). UAB, Bellaterra.

Espadalé, J., 2002. L'aplicació de màquines en la manufactura surotapera. Revista de Girona, 213, 76-83.

Ferrer, Ll., 1994. Notas sobre la familia y el trabajo de la mujer en la Cataluña central (siglos XVIII-XIX). Boletín de la ADHE. 12, 199-232.

Gálvez, L., 2000. Género y cambio tecnológico: rentabilidad económica y política del proceso de industrialización del monopolio de tabacos en España (1887-1945). Revista de Historia Económica. 1, 11-45.
Garcia Balañà, A., 2004. La fabricació de la fàbrica. Treball i política a la Catalunya cotonera (1784-1874). Abadia de Montserrat, Barcelona.

García-Zúñiga, M., 2011. La evolución de los días de trabajo en España, 1250-1918. En: X Congreso de la AEHE, Carmona.

Gordon, D. M., Edwards, R. y Reich, M., 1986. Trabajo segmentado, trabajadores divididos. Ministerio de Trabajo, Madrid.

Huberman, M., 1996. Escape from the market. Negotiating work in Lancashire. CUP, Cambridge.

Instituto de Reformas Sociales, 1914. La jornada de trabajo en la industria textil. Sucesores Minuesa de los Ríos, Madrid.

Jacoby, S. M., 1988. El desarrollo de los mercados internos de trabajo en las empresas industriales americanas. En: Osterman, P. (comp.). Los mercados internos de trabajo. Ministerio de Trabajo, Madrid, pp. 37-86.

Jacoby, S. M y Sharma, S., 1992. Employment Duration and Industrial Labor Mobility in the United States, 1880-1980. Journal of Economic History. 52 (1), 161-179.

Lazonick, W., 1979. Industrial Relations and Technical Change: The Case of the Self-Acting Mule. Cambridge Journal of Economics. 3 (3), 231-262.

Lipartito, K., 1994. When Women Were Switches: Technology, Work, and Gender in the Telephone Industry, 1890-1920. American Historical Review. 99 (4), 1075-1111.

Llonch, M., 2004. Jornada, salarios y costes laborales en el sector textil catalán (1891-1936)- Revista de Historia Industrial. 26, 101-140.

Maluquer de Motes, J. y Llonch, M., 2005. Trabajo y relaciones laborales. En: Carreras, A. y Tafunell, X. (coords.). Estadísticas Históricas de España. Madrid, BBVA, pp.1154-1213.

Martínez Quintanilla, P., 1865. La provincia de Gerona. Datos estadísticos. F. Dorca, Girona.

Medir, R., 1953. Historia del gremio corchero. Alhambra, Madrid.

Muñoz Abeledo, L., 2010. Género, trabajo y niveles de vida en la industria conservera de Galicia, 1870-1970. Icaria, Barcelona.

Owen, L. J., 1995. Worker Turnover in the 1920s: What Labor-Supply Arguments Don't Tell Us. Journal of Economic History. 55 (4), 822-841.

Parejo Moruno, F. M., 2010. El negocio del corcho en España durante el siglo xx. Banco de España, Madrid.

Pelegrí, J., 1919. La repercussió de la Gran Guerra en la comarca del Baix Empordà, reproducido en L'Estoig, 5, 1997.

Reid, D. A., 1976. The Decline of Saint Monday, 1776-1876. Past and Present. 71, 76-101.

Roger, M., 1911. Els tipus socials de la producció surotapera. L'Avenç, Barcelona.

Ros, R. y Sala, P., 2014. Redes comerciales en la manufactura corchera catalana antes de 1914. El ejemplo de Genís y Cia. Revista de Historia Industrial. 56 49-80.

Rule, J., 1981. The Experience of Labour in Eighteenth-Century English Industry. St. Martin's Press, New York.

Sala, P., 1998. Obrador, indústria i aranzels al districte surer català (1830-1930). Recerques. 37, 109-135.

Sala, P., 2003. Manufacturas de Corcho S. A. (antiga Miquel \& Vinke). Museu del Suro, Palafrugell.

Sancho, A., 2004. El mercado de trabajo en una empresa flexible: la fundición Averly de Zaragoza (1880-1930). Revista de Historia Económica. 22, 425-469.

Serrat Banquells, E., 1897. La industria corchotaponera en la provincia de Gerona. Asociación literaria de Gerona. Paciano Torres, Girona.

Sonenscher, M., 1989. Work and wages. Natural law, politics and the eighteenth-century French trades. CUP, Cambridge.

Stephenson, J. Z., 2018. Looking for work? Or looking for workers? Day and hours of work in London construction in the eighteenth century. University of Oxford Discussion Papers in Economic and Social History, 162.

Thompson, E. P, 1979. Tiempo, disciplina de trabajo y capitalismo industrial. En: Tradición, revuelta y consciencia de clase. Crítica, Barcelona, pp. 239-293.

Vicente, M., 2000. Artisans and Work in a Barcelona Cotton Factory (1770-1816). International Review of Social History. 45 (1), 1-23.

Vila Saglietti, H., 1892. O sobreiro (el alcornoque) y su explotación comercial ante las relaciones internacionales hispanoportuguesas. Paciano Torres, Girona.

Voth, H. J., 2000. Time and Work in England. 1750-1830. Clarendon, Oxford.

Zapata, S., 1996. Corcho extremeño y andaluz, tapones gerundenses. Revista de Historia Industrial. 10, 37-68.

Zapata, S., 2002. Del suro a la cortiça. El ascenso de Portugal a primera potencia corchera del mundo. Revista de Historia Industrial. 22, 109-137. 